\title{
Socio-demographic correlates of treatment response among patients with schizophrenia in a tertiary hospital in South-East Nigeria.
}

\author{
Mark S. Ezeme, Richard Uwakwe, Appolos C. Ndukuba, Monday N.Igwe, Paul C. Odinka, \\ Kennedy Amadi, Nichodemus O. Obayi.
}

1. ESUT Teaching Hospital Parklane, Psychiaatry

\begin{abstract}
Background: Many patients with schizophrenia respond poorly to antipsychotic medication. Few studies have systematically examined the relationship of social and demographic characteristics of these patients to treatment response in our environment. Objective: To identify the social and demographic variables associated with treatment response in patients with schizophrenia. Method: A total of 172 participants with a diagnosis of schizophrenia receiving antipsychotics took part in the study. Participants were consecutively recruited involving patients presenting for the first time, or relapsed patients who had stopped antipsychotics in the previous six months. Both in-patients and out-patients who met the inclusion criteria were studied. Socio-demographic interview schedule and the Positive and Negative Syndrome Scale (PANSS) were administered at the initial encounter and between 4 and 6 weeks, subsequently.

Results: Defining good treatment response as $\geq 20 \%$ reduction in PANSS score, $68 \%$ had a good response while $32 \%$ had poor response. Good response to treatment was associated with late age of onset of illness, satisfactory family relationship, acquisition of skilled occupation and being married. However, there was no association between treatment response and gender.

Conclusion: Knowledge about these variables in relation to treatment response would improve mental health services as regards articulation of prognosis and psycho education.
\end{abstract}

Keywords: Socio-demographic correlates, schizophrenia, South-East Nigeria.

DOI: http://dx.doi.org/10.4314/ahs.v16i4.21

Cite as: Ezeme MS, Uwakwe R, Ndukuba AC, Igwe MN, Odinka PC, Amadi K, Obayi NO. Socio-demographic correlates of treatment response among patients with schizophrenia in a tertiary hospital in South-East Nigeria. Afri Health Sci2016;16(4): 1036-1044. http:/ / dx.doi. org/10.4314/abs.v16i4.21

\section{Introduction}

Schizophrenia is a severe and debilitating mental disorder, characterized by disturbances in thought processes, perception and emotional responses. It most commonly affects individuals in their adolescence and early adulthood. It is a heterogeneous disorder in terms of the nature of the illness and response to antipsychotic treatment. For example, some patients are refractory to treatment from the outset, while others appear to acquire treatment refractoriness at some stage for reasons that are poorly understood. ${ }^{1}$ Gureje et $\mathrm{al}^{2}$ in a study of 120 clinically stable out-patients in a clinic in Nigeria, examined the social, occupational and residential outcomes of schizophrenia after 13 years. They found that a substantial proportion of patients showed a moderate to severe degree of dis-

\section{Corresponding author:}

Mark S. Ezeme,

ESUT Teaching Hospital Parklane, Psychiaatry

Email: marksunday34@hotmail.com,

sundaymark34@gmail.com

African Health Sciences Vol 16 Issue 4, December, 2016 ability in the areas of occupation and social contact. Four percent were homeless or of unstable abode.

Adequate response to treatment has been defined as at least a $20 \%$ reduction in symptoms as measured by rating scales. ${ }^{3}$ The time course of response to antipsychotic therapy has been extensively evaluated, and the original belief that it took between 6 and 8 weeks to determine a therapy's effectiveness in patients with schizophrenia has largely been abandoned ${ }^{4}$ It has been reported that the quality of symptomatic or subjective change within a few days of treatment predicts the response to several weeks of treatment..$^{5-7}$

Early symptom response significantly improved the prediction of outcome, suggesting that early monitoring of treatment response may be useful in clinical practice. ${ }^{8}$ Using a broad definition, treatment resistant schizophrenia (TRS) would imply any persistence of any symptom or abnormal behaviour or sequelae in patients treated for schizophrenia.' This definition includes chronic illness and failure to achieve a decline in Brief Psychiatric Rating Scales (BPRS) scores between 20\% and 30\% despite two adequate trials with antipsychotics from two different 
classes. ${ }^{10}$ A 4 to 6 week trial of 400 to $600 \mathrm{mg}$ per day of chlorpromazine or its equivalent is currently accepted as the standard for an adequate treatment trial. ${ }^{11-13}$

Ohaeri $^{14}$ in a retrospective, consecutive case record analysis of a 7-year follow-up study of 142 patients at the Ibadan teaching hospital, using outcome criteria that included presence of positive and negative symptoms of schizophrenia and social adjustment in the previous 12 months, found a non-significant trend for more females to be without psychotic symptoms, and males performed significantly better in social adjustments. Szymanski et al, ${ }^{15}$ demonstrated that female patients had a later age of onset and better treatment response than the men. Women with schizophrenia tend to have better pre-morbid functioning, distinct symptom profile, a better course of illness, and different structural brain abnormalities and cognitive deficits. It has been hypothesized that estrogen, with effects on both neuro-development and neuro-transmission, may play a protective role in women with schizophrenia. ${ }^{16}$ However, the relationship between putative sex-related variance in symptomatology and inter-morbid functioning has not been fully understood.

Gureje ${ }^{17}$ studied a consecutive series of 214 patients with schizophrenia to determine gender differences in age at onset of illness and socio-demographic attributes. He found that male patients had earlier ages of onset than females. By the time they were 30 years of age, $83 \%$ of males had already become ill compared to $66 \%$ of females. The clinical presentation of schizophrenia at an unusually early age has been associated with pre-morbid developmental abnormalities, poor response to neuroleptic treatment, greater admission rates, and poor prognosis. ${ }^{18}$ Onset of schizophrenia before 18 years of age is commonly categorized as early-onset while onset before 13 years is considered as childhood-onset schizophrenia. ${ }^{19}$

Unsatisfactory family relationships most times manifest in form of hostility, emotional over-involvement and criticism directed to the patient by the family members or caregiver(s). This was termed emotional expression by Brown ${ }^{20}$ and later by Vaughn and Leff ${ }^{21}$ as quoted by Abaoub et al. ${ }^{22}$ On the other hand, warmth and good remarks from the family usually bring about satisfactory relationships. Bebbington et $\mathrm{al}^{23}$ in the article that summarized results of aggregate analysis of 25 studies on expressed emotions, demonstrated that expressed emotion gave a robust prediction of relapse, irrespective of location, culture and sex. Married individuals are more likely to have social support, better problem solving ability and self esteem. On the other hand, marriage can also become source of stress and high expressed emotion that may lead to frequent relapses. ${ }^{24}$

Work is a frequently stated goal of people with schizophrenia, ${ }^{25}$ but their employment rate is low. Employment rates of patients with schizophrenia in Europe range from $8-35 \%{ }^{26}$ Hijzen et $\mathrm{a}^{27}$ in a study of international outsourcing and skill structure of labour demand in the United Kingdom, distinguished workers into 3 skilled groups: skilled, semi-skilled, and unskilled. Priebe et al, ${ }^{28}$ examined attitudes toward work, work incentives and impact of work on quality of life for people with schizophrenia in 3 sites. When participants from all sites were combined, employed ones displayed less psychopathology and significant advantages in terms of objective and subjective measures of income and quality of life. Work history and negative or cognitive symptoms of schizophrenia have consistently been found to be predictors of employment status. ${ }^{29,30}$ However, for many middle-class people, work is seen as a source of identity, self respect, and status. But in one US study, ${ }^{31}$ many participants with serious mental illness reported available work as hard, stressful, dirty, demanding, and fast-paced. Moreover, the jobs were too low grade, poorly reimbursed with associated loss of leisure time and the risk of increased symptoms and relapse.

Awareness of early response or non-response to antipsychotic treatment can direct clinicians in formulation of short-term and long-term measures to help patients attain optimal outcome. This study was designed to assess socio-demographic correlates of treatment responses in patients treated for schizophrenia.

\section{Methods \\ Study setting}

The study was done at the Federal neuropsychiatric hospital, Enugu. The hospital was initially a prison asylum during the colonial era in Nigeria. In 1962, it was converted to an outpatient clinic of the general hospital Enugu, under the old Eastern region. It was taken over by the federal government in 1995 and is the only federal government funded psychiatric hospital in the South-East region of Nigeria. The hospital provides psychiatric services to residents of Enugu state and receives referrals from all the South-Eastern states of Nigeria as well as from parts of the North-Central and South-south regions.

African Health Sciences Vol 16 Issue 4, December, 2016 
On the average, the hospital provides services to about 1550 patients monthly at the Emergency and Crisis Intervention Unit, out of which about 180 are new patients (Information from Federal Neuro-psychiatric Hospital, Enugu Medical Records). There is a 24 hour service at the emergency and crisis intervention unit where new and defaulted patients and those presenting outside working hours and weekends are seen. This unit has one ward of three beds each for males and females for purposes of patients' observation. Patients for admission are transferred from the emergency and crisis intervention unit to the wards (male or female) after review by consultants psychiatrists.

The hospital has a bed capacity of 104; 62 beds in the male wards and 42 beds in the female wards. Bed occupancy is predominantly $100 \%$ in male and female wards at any point in time. Discharged patients are followed up in the out-patient department. The clinics are run on working days except Wednesday which is used for academic activities. An average of 120 patients is seen in a day in these clinics, and about half of them are patients with schizophrenia.

\section{Ethical approval}

Approval for this study was obtained from the Ethics Committee of the Federal Neuropsychiatric Hospital Enugu. Written informed consent to participate in the study was obtained from all participants and or their caregiver(s).

\section{Participants and sampling method}

Participants were patients diagnosed of schizophrenia using International Classification of Diseases $10^{\text {th }}$ edition (ICD-10) or Diagnostic and Statistical Manual $4^{\text {th }}$ edition (DSM-IV) diagnostic criteria who presented to the hospital for the first time. Also recruited were patients who had previously been commenced on treatment for schizophrenia, who had not taken their medication in the preceding 6 months and currently met criteria for schizophrenia. A period of 6 months was chosen to ensure that there was an adequate 'wash-out' of the antipsychotics. Patients with any other concurrent severe mental disorder apart from schizophrenia or a severe medical illness such as impaired consciousness that made it impossible to answer questions were excluded from the study. Recruited patients were commenced on either typical or atypical antipsychotics.

African Health Sciences Vol 16 Issue 4, December, 2016
It was a 4-6 weeks naturalistic outcome study. One hundred and seventy-two consecutive participants aged 18-64 years who presented at the emergency and crisis intervention unit who met inclusion criteria were recruited in the study whether or not they were admitted in the ward. The authors administered the instruments: Socio-demographic questionnaire and Positive and Negative Syndrome Scale (to assess the severity of symptoms) to all the participants. The same process was repeated 4-6 weeks after the initial interview (to ascertain the degree of treatment response). The study was carried out between September, 2012 and January, 2013. Participants who could not understand English language were interviewed with the translated Igbo version of the instruments.

\section{The socio-demographic questionnaire}

This questionnaire was designed to provide basic information about the participant's age, gender, marital status, occupation, level of education, religious affiliation, and ethnic background.

\section{The Positive and Negative Syndrome Scale (PANSS)} This is a 30-item, 7-point rating instrument that has adapted 18 items from Brief Psychiatric Rating Scale BPRS $^{32}$ and 12 items from Psychopathology Rating Schedule (PRS). ${ }^{35}$ The 30 parameters assessed on the PANSS are the positive scale, negative scale and general psychopathology scale. The positive scale consists of delusions, conceptual disorganization, hallucinatory behaviour, excitement, grandiosity, suspiciousness/ persecution. The negative scale consists of blunted affect, emotional withdrawal, poor rapport, passive/ apathetic social withdrawal, difficulty in abstract thinking, lack of spontaneous / flow of conversation, stereotyped thinking. The general scale consists of somatic concern, anxiety, guilt feeling, tension, mannerism/posturing, depression, motor retardation, uncooperativeness, unusual thought content, disorientation, poor attention, disturbance of volition, lack of judgement/insight, poor impulse control, pre-occupation, active social avoidance. Total score is by simple summation, higher scores indicate more severe symptoms.

The reliability of the PANSS has been examined using coefficient alpha to analyze its internal consistency and contribution of the component items. Overall, the alpha coefficients for the positive and negative scales, the general psychopathology scale were $0.73,0.83$ and 0.79 respectively $(\mathrm{p}>.001) . .^{33}$ 


\section{Data analysis}

Analysis was done with the Statistical Package for Social Science (SPSS) version 16 for windows (ref). Participants were grouped according to the change in their PANSS score, comparing the initial and second measurements. The PANSS scores at the initial interview was denoted as PANSS1, while PANSS score at the follow-up interview was denoted as PANSS2. Those whose percentage reduction in PANSS scores were $\geq 20 \%$ were classified as improved, while those whose percentage reduction in PANSS scores were $<20 \%$ were classified as un-improved. Results were calculated as frequencies, means and standard deviations. Chi-square, was used to analyse categorical variables like sex, marital status, educational attainment etc; while t-test was used to analyse continuous variables like age. Paired t-test was applied to compare the PANSS scores at $1^{\text {st }}$ and $2^{\text {nd }}$ interview. Reduction or change in PANSS score was used as the dependent variable, while social and demographic factors were used as the independent variables. Significance level was computed at $\mathrm{p}<0.05$. Participants with semi-skilled and skilled occupation were grouped together as skilled.

\section{Results}

Sociodemographic Characteristics of the participants.

A total of 191 participants were recruited for the study; 19 were lost to follow-up for the second interview, leaving a sample size of 172 participants for analysis. One hundred and twelve $(65.1 \%)$ of the participants were out-patients while $60(34.9 \%)$ were admitted.

Eight-nine $(51.7 \%)$ of the participants were females and $83(48.3 \%)$ were males. They were aged $18-60$ years with a mean age of $32.7+8.7,29.2+8.0$ years.

The age at first onset of illness ranged from 14-52 years with a mean age of $29.2+8.0$ years.

One hundred and twenty three $(71.5 \%)$ participants were not married (single, separated, divorced or widowed), majority of the participants 165 (95.9\%) were Christians, while $170(98.8 \%)$ had some form of formal education. Eighty-eight (51.2\%) participants were unemployed and dependent and 108 (62.8\%) were unskilled. One hundred and twelve $(65.1 \%)$ participants had satisfactory relationships with their family. Table 1 shows the socio-demographic characteristics of the participants.

Table 1: The socio-demographic characteristics of the participants.

\begin{tabular}{|c|c|c|}
\hline \multicolumn{2}{|c|}{ Variables } & \multirow{2}{*}{$\begin{array}{l}\mathbf{N}(\%) \\
83(48.3) \\
89(51.7)\end{array}$} \\
\hline Gender & $\begin{array}{c}\text { Male } \\
\text { Female }\end{array}$ & \\
\hline \multirow{5}{*}{$\begin{array}{l}\text { Age at first onset of } \\
\text { illness (years) }\end{array}$} & $10-18$ & $9(5.2)$ \\
\hline & $19-30$ & $86(50.0)$ \\
\hline & $31-40$ & $62(36.0)$ \\
\hline & $41-50$ & $13(7.6)$ \\
\hline & $51-60$ & $2(1.2)$ \\
\hline Range(years) & $14-52$ & \\
\hline Mean \pm sd (years) & $29.2 \pm 8.0$ & \\
\hline Median (years) & 29.0 & \\
\hline Current Marital & Single & $104(60.5)$ \\
\hline \multirow[t]{4}{*}{ Status } & Married & $49(28.5)$ \\
\hline & Separated & $12(7.0)$ \\
\hline & Widowed & $4(2.3)$ \\
\hline & Divorced & $3(1.7)$ \\
\hline \multirow[t]{3}{*}{ Religion } & Christianity & $165(95.9)$ \\
\hline & Islam & $3(1.8)$ \\
\hline & African traditional religion & $4(2.3)$ \\
\hline \multirow[t]{5}{*}{ Educational Status } & Tertiary education & $64(37.2)$ \\
\hline & Senior secondary school & $62(36.0)$ \\
\hline & Junior secondary school & $22(12.8)$ \\
\hline & Primary school & $22(12.8)$ \\
\hline & No formal education & $2(1.2)$ \\
\hline \multirow{2}{*}{$\begin{array}{l}\text { Current Employment } \\
\text { Status }\end{array}$} & Unemployed & $88(51.2)$ \\
\hline & Employed & $84(48.8)$ \\
\hline \multirow[t]{3}{*}{ Occupation } & Skilled & $32(18.6)$ \\
\hline & Semi-skilled & $32(18.6)$ \\
\hline & Unskilled & $108(62.8)$ \\
\hline \multirow[t]{2}{*}{ Family Relationship } & Satisfactory & $112(65.1)$ \\
\hline & Unsatisfactory & $60(34.9)$ \\
\hline
\end{tabular}

The profile of the participants according to PANSS Scores

PANSS 1: The scores ranged between 45.0 to 131.0, with a mean score of $82.1+13.1$ and median of 83.0.

PANSS 2: The scores ranged between 30.0 to 118.0 , with a mean score of $57.5+18.5$ and median of 51.0 . The PANSS 1 and PANSS 2 difference ranged from -10.0 to 98.0, with a mean of $24.7+16.4$ and median of 25.0.

The participants were categorized into "improved" and "unimproved". The majority, 117 (68\%) of the partici- 
pants improved while $55(32 \%)$ did not improve. Among those that improved, $52(44.4 \%)$ were males while 65 (55.6\%) were females. Among those who did not improve, $31(56.4 \%)$ were males while $24(43.6 \%)$ were females.
On each of the positive scale item, the initial PANSS score was higher than the follow-up PANSS score. Table 2 shows the profile of the participants according to initial and follow-up mean scores on the PANSS positive scale domain.

Table 2: The profile of the participants according to initial and follow-up mean scores on PANSS positive scale items.

\begin{tabular}{lllll}
\hline \multirow{2}{*}{ Variables } & PANSS1 & PANSS2 & & \\
& Mean $\pm \mathrm{SD}$ & Mean $\pm \mathrm{SD}$ & $\mathrm{t}$ & $\mathrm{p}$-value \\
\hline Delusions & $3.7 \pm 1.0$ & $2.3 \pm 1.1$ & 15.8 & $<0.001$ \\
Conceptual disorganization & $2.8 \pm 1.4$ & $1.9 \pm 1.1$ & 9.6 & $<0.001$ \\
Hallucinatory behaviour & $3.3 \pm 1.32$ & $2.1 \pm 1.2$ & 12.0 & $<0.001$ \\
Excitement & $2.9 \pm 1.5$ & $1.7 \pm 1.1$ & 10.7 & $<0.001$ \\
Grandiosity & $2.3 \pm 1.6$ & $1.7 \pm 1.3$ & 7.4 & $<0.001$ \\
Suspiciousness/persecution & $4.1 \pm 1.3$ & $2.5 \pm 1.2$ & 15.0 & $<0.001$ \\
Hostility & $3.0 \pm 1.5$ & $1.8 \pm 1.5$ & 11.1 & $<0.001$ \\
\hline
\end{tabular}

On each of the negative scale item, the initial PANSS score was higher than the follow-up PANSS score. Table
3 shows the profile of the participants according to initial and follow-up mean scores on the PANSS negative scale domain.

Table 3: The profile of the participants according to initial and follow-up mean scores on PANSS negative scale items.

\begin{tabular}{|c|c|c|c|c|}
\hline & PANSS1 & PANSS 2 & & \\
\hline Variables & Mean \pm SD & Mean \pm SD & $\mathrm{t}$ & p-value \\
\hline Blunted affect & $3.3 \pm 1.4$ & $2.4 \pm 1.3$ & 13.1 & $<0.001$ \\
\hline Emotional withdrawal & $3.6 \pm 1.3$ & $2.4 \pm 1.3$ & 14.6 & $<0.001$ \\
\hline Poor rapport & $2.4 \pm 1.7$ & $1.7 \pm 1.1$ & 6.7 & $<0.001$ \\
\hline $\begin{array}{l}\text { Passive/apathetic social } \\
\text { withdrawal }\end{array}$ & $3.5 \pm 1.4$ & $2.4 \pm 1.3$ & 11.8 & $<0.001$ \\
\hline $\begin{array}{l}\text { Difficulty in abstract } \\
\text { thinking }\end{array}$ & $2.4 \pm 1.1$ & $1.9 \pm 0.9$ & 8.1 & $<0.001$ \\
\hline $\begin{array}{l}\text { Lack of spontaneous/flow } \\
\text { of conversation }\end{array}$ & $2.9 \pm 1.7$ & $1.9 \pm 1.2$ & 9.4 & $<0.001$ \\
\hline Stereotyped thinking & $1.9 \pm 1.0$ & $1.6 \pm 0.9$ & 5.5 & $<0.001$ \\
\hline
\end{tabular}

On each of the general scale item, the initial PANSS score was higher than the follow-up PANSS score. Table
4 shows the profile of the participants according to initial and follow-up mean scores on the PANSS general scale domain. 
Table 4: The profile of the participants according to initial and follow-up mean scores on PANSS general scale items.

\begin{tabular}{|c|c|c|c|c|}
\hline Variables & $\begin{array}{c}\text { PANSS1 } \\
\text { Mean } \pm \text { SD }\end{array}$ & $\begin{array}{r}\text { PANSS } 2 \\
\text { Mean } \pm \text { SD }\end{array}$ & $\mathrm{t}$ & p-value \\
\hline Somatic concern & $2.7 \pm 1.4$ & $2.1 \pm 1.2$ & 8.2 & $<0.001$ \\
\hline Anxiety & $1.9 \pm 1.0$ & $1.3 \pm 0.6$ & 8.4 & $<0.001$ \\
\hline Guilt feeling & $2.0 \pm 1.2$ & $1.3 \pm 0.7$ & 7.3 & $<0.001$ \\
\hline Tension & $2.2 \pm 1.2$ & $1.5 \pm 0.8$ & 8.8 & $<0.001$ \\
\hline Mannerism/posturing & $1.8 \pm 1.6$ & $1.4 \pm 1.0$ & 5.7 & $<0.001$ \\
\hline Depression & $2.4 \pm 1.0$ & $1.7 \pm 0.8$ & 9.5 & $<0.001$ \\
\hline Motor retardation & $2.8 \pm 1.6$ & $2.2 \pm 1.3$ & 7.4 & $<0.001$ \\
\hline Uncooperativeness & $3.3 \pm 1.6$ & $2.0 \pm 1.3$ & 11.7 & $<0.001$ \\
\hline Unusual thought content & $2.5 \pm 1.2$ & $1.9 \pm 1.1$ & 7.7 & $<0.001$ \\
\hline Disorientation & $2.0 \pm 1.0$ & $1.47 \pm 1.2$ & 8.1 & $<0.001$ \\
\hline Poor attention & $2.2 \pm 1.2$ & $1.6 \pm 0.8$ & 8.5 & $<0.001$ \\
\hline Lack of judgment/insight & $4.5 \pm 1.8$ & $3.9 \pm 2.0$ & 7.1 & $<0.001$ \\
\hline $\begin{array}{l}\text { Disturbance } \\
\text { volition }\end{array}$ & $2.4 \pm 1.5$ & $1.9 \pm 1.2$ & 6.9 & $<0.001$ \\
\hline Poor impulse control & $2.8 \pm 1.5$ & $1.8 \pm 1.1$ & 9.9 & $<0.001$ \\
\hline Preoccupation & $2.0 \pm 1.3$ & $1.6 \pm 0.9$ & 6.1 & $<0.001$ \\
\hline Active social avoidance & $3.2 \pm 1.8$ & $1.9 \pm 1.2$ & 11.4 & $<0.001$ \\
\hline
\end{tabular}

\section{Association between socio-demographic variables} and treatment response.

The clinical improvement of the participants was associated with late age of onset of illness, being married, satisfactory family relationship and acquisition of skilled

occupation. However, there was no association between treatment response and gender.

Table 5 shows the relationship between age of onset of illness, gender, marital status, family relationship, occupation and treatment response.

Table 5: Relationship between age of onset of illness, gender, marital status, family relationship, occupation and treatment response.

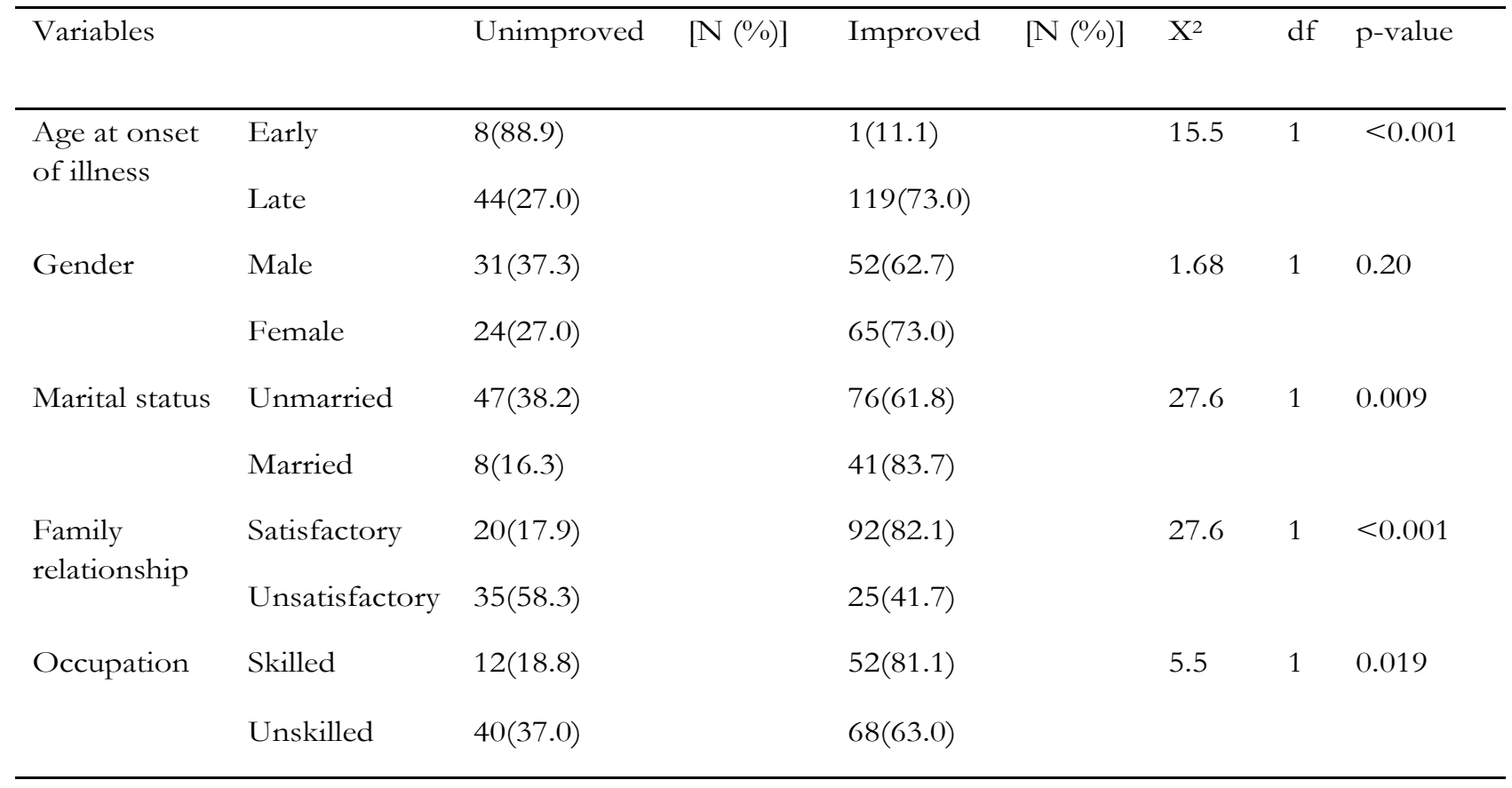




\section{Discussion}

\section{Treatment response}

Overall, there was a marked reduction in PANSS scores during the follow-up assessments, involving the positive, negative, and general scale domains. This might have resulted from the therapeutic effect of the anti-psychotic medications administered from the initial consultation leading to amelioration of symptoms. This result is in concordance with Buchanan et $\mathrm{al}^{34}$ who found that antipsychotic drugs are first line treatment for schizophrenia, and randomized trials have shown anti-psychotics to reduce positive symptoms such as hallucinations, delusions and suspiciousness compared to placebos. In the present study, $68 \%$ of the participants improved, while $32 \%$ did not improve. A similar finding was obtained from a review study on conventional anti-psychotic medications for schizophrenia. Anti-psychotics were found to eliminate acute symptoms of schizophrenia to a tolerable level in about $70 \%$ of patients. ${ }^{35}$

\section{The relationship between socio-demographic vari- ables and response to treatment.}

There was no gender difference in response to treatment in the present study. One reason may perhaps be the relatively high proportion of late-onset cases. Nigerian and Western studies have reported better treatment response in females compared to males. ${ }^{36,37}$ Leung et $\mathrm{al}^{36}$ and Ochoa $^{37}$ in review articles reported that males have consistently had earlier onset of illness, poorer pre-morbid functioning and different pre-morbid behavioural predictors. According to these authors, males showed more negative symptoms and cognitive deficits, with greater structural brain and neuro-physiological abnormalities.

Females displayed more affective symptoms, auditory hallucinations and persecutory delusions with rapid and greater responsiveness to anti-psychotic side-effects. Canuso and Pandina ${ }^{38}$ in a review article on gender and schizophrenia reported that differences in gender responses or outcome in schizophrenia arise from the interplay between hormonal and psychosocial factors. Though studies have shown gender differences in schizophrenia, some scholars call into question the universality of these differences. Kindler and Walsh ${ }^{39}$ in their epidemiological study in Ireland, were unable to show any demonstrable impact of gender on the presentation and course of schizophrenia which is in consonance with the present study. Ohaeri ${ }^{14}$ in a consecutive case records study to determine outcome in a 7-26 year follow-up of patients

African Health Sciences Vol 16 Issue 4, December, 2016 with schizophrenia, found non-significant trend for more female participants to be without psychotic symptoms, and the males performed significantly better in social outcome measures. By and large, there are conflicting reports on the influence of gender on response to treatment, and further studies in this area are needed to provide relevant and specific information with the view to improving patients' condition.

The mean age at the first onset of illness found in this study was $29.2 \pm 8.0$ years, and this may be due to exclusion of participants aged below 18 years. Meltzer et $\mathrm{al}^{40}$ in their study of consecutively admitted patients to a university hospital research based programme investigated age at onset and gender in relation to neuroleptic resistance, and found mean ages at onset in the neuroleptic-resistant males to be $19.4 \pm 4$.7years and neuroleptic-resistant females as $20.1 \pm 6.3$ years. There was a significant association between early age of onset of schizophrenia with poor treatment response in the present study. This is similar to the finding in previous studies. ${ }^{18,41}$

The present study showed that participants with good family relationship made better improvement compared with those participants who had unsatisfactory relationship. The fact that the majority of the participants live and were brought to the hospital by their family may be a sign of a satisfactory relationship between them. In keeping with this point is the report by a review article that findings from Asia, Africa, and Middle Eastern countries suggest that some positive aspects are associated with living with a family member who has schizophrenia. ${ }^{42}$

Schwartz and Gidron ${ }^{43}$ in a descriptive study found that Israeli parents reported satisfaction with their care-giving roles for their ill relatives. Unsatisfactory family relationships most times manifests in the form of hostility, emotional over-involvement and criticisms directed to the patient by the caregiver(s) and this is termed emotional expression by Brown ${ }^{20}$ and later, Vaughn and Leff. ${ }^{21}$ Stresses and care burden consequent to living with a family member with schizophrenia; resulting in high expressed emotion have been associated with higher rates of relapse compared with those with low expressed emotion families. ${ }^{44}$

The lifetime emotional, social, and financial consequences experienced by individuals with schizophrenia, have significant effects on their families. The family respons- 
es to having a member with schizophrenia include: care burden, fear and embarrassment about illness signs and symptoms, uncertainty about the course of the illness, lack of social support, and stigma. ${ }^{42}$

Married participants were more likely to respond to anti-psychotic treatment compared with the unmarried participants in the present study. This is expected because married individuals are more likely to have social support, better problem solving ability and self-esteem. On the other hand, marriage can also become a source of stress and high expressed emotion that may lead to frequent relapses. $^{24}$

Participants with skilled occupation responded better to treatment than the unskilled ones. These skilled participants may have had a late onset illness, good premorbid functioning, work history and quality of $\operatorname{life}^{28}$, compared with the unskilled ones. However contrary to this result, work can be perceived as hard, stressful and loss of leisure, and hence increase the risk of relapse ${ }^{31}$.

\section{Limitations of the study}

This study employed a short term follow-up period which may not be enough to observe the various responses of the study participants. This was a hospital-based study, and the findings may not be generalized to the entire population of patients with schizophrenia in Enugu or Nigeria. The findings of the study demonstrated mere associations; hence causal implications cannot be inferred. Reasonable proportions of the data collected was based on self-report and subjective assessments. It is possible that some recall or other biases may have crept in, in some instances. The contributions of genetics, other clinical variables and treatment modalities to treatment response were not taken into consideration.

\section{Conclusion}

The findings of this study provide useful information for identifying individuals at risk of poor response to treatment so that appropriate measures can be taken.

\section{Conflict of interest}

None to declare.

\section{References}

1. Lieberman JA, Koreen AR, Chakos M, Sheitman B, Woerner M, Alvir JM et al. Factors influencing treatment response and outcome of first-episode Schizophrenia: implications for understanding the Pathophysiology of Schizophrenia. J Clin Psychiatry. 1996; 57 Suppl 9: 5-9.

2. Gureje O, Bamidele R. Thirteen-year social outcome among Nigerian outpatients with schizophrenia. Social Psychiatry Psychiatr Epidemiol. 1999; 34 (3): 147-51.

3. Shim SS. Treatment Resistant Schizophrenia (Strategies for recognizing Schizophrenia and Treating to Remission). Psychiatric Times. 2009; 26(8): 1-4.

4. Agid O, Kapur S, Arenovich T, Zipursky RB. Delayed-onset hypothesis of antipsychotic action: a hypothesis tested and rejected. Arch Gen Psychiatry. 2003;60: 1228-1235.

5. May PRA, van Putten T, Yale C. Predicting outcome of antipsychotic drug treatment from early response. Am J psychiatry. 1980; 137: 1088 - 1089.

6. Nedopil N, Ruther E. Initial improvement as predictor of outcome of neuroleptic treatment. Pharmacopsychiatrica. 1981; 14: $205-207$.

7. Hogan TP, Awad AG, Eastwood MR. Early subjective response and prediction of outcome to neuroleptic drug therapy in schizophrenia. Can J Psychiatry. 1985; 30: 246 $-248$.

8. Lipkovich IA, Deberdt W, Csernansky JG, Buckley P, Peuskens J, Kollack - Walker S et al. Defining "good" and "poor" outcomes in patients with schizophrenia or schizoaffective disorder: a multidimensional data-driven approach. Psychiatr Research. 2009; 170 (2-3): 161 - 7.

9. Caspi A, Davidson M, Tamminga CA. Treatment-refractory schizophrenia. Dialogues Clin Neurosci. 2004; 6(1): 61-70.

10. Kane J, Honigfield G, Singer J, Melter H. Clozapine for treatment-resistant schizophrenia. A double blind comparison with chlorpromazine. Arc. Gen Psychiatry. 1988; 45: 789-796.

11. Kane JM, Marder SR. Psychopharmacologic treatment of schizophrenia. Schizophr Bull. 1993; 19: 287-302. 12. Barness TR, McEvedy CJ. Pharmacological treatment strategies in non-responsive schizophrenia patients. Int Clin Psychopharmacol. 1996; 11 (suppl2): 67-71.

13. Dixon LB, Lehman AF, Levine J. Conventional antipsychotic medications of schizophrenia. Schizophr Bull. 1995; 21: 567-577.

14. Ohaeri JU. Long-term outcome of treated schizophrenia in Nigerian cohort. Retrospective analysis of 7-year follow-ups. J Nerv'Ment Dis. 1993; 181 (8): 514-6.

15. Szymanski S, Lieberman JA, Alvir JM, Mayerhoff D, Loebel A, Geisler S et al. Gender difference in onset of illness, treatment response, course and biologic indexes in 
first-episode schizophrenia patients. Am J Psychiatry. 1995; 152 (5): $698-703$.

16. Canuso CM, Pandina G. Gender and schizophrenia. Psychopharmacol Bull. 2007; 40(4): 178-90.

17. Gureje O. Gender and schizophrenia: age at onset and sociodemographic attributes. Acta Psychiatr Scand. 1991; 83 (5): 402-5.

18. Vyas NS, Gogtay N. Treatment of early onset schizophrenia: recent trends, challenges and future considerations. Front Psychiatry. 2012; 3: 29.

19. McClellan J, Werry J. Practice parameter for assessment and treatment of children and adolescent with schizophrenia. J the Am Child Adoles Psychiatry. 2001; 40 (suppl 7): 4s-23s.

20. Brown GW. Experiences of discharged chronic schizophrenic mental hospital patients in various types of living groups. Milbank Mem Fund Q. 1959; 37: 105-31.

21. Vaughn C, Leff J. The measurement of expressed emotion in the families of psychiatric patients. Bri J Soc Clin Psychology. 1976; 15:157-165.

22. Abaoub A, Vidon G. Update on "expressed emotions". Encephale. 2000; 26 (3): 81 - 86.

23. Bebbington P, Kinpers L. The clinical ultility of expressedemotion in schizophrenia. Acta Psychiatr Scand Suppl. 1994; 382: 46 - 53.

24. Ivanovic M, Vuletic Z, Bebbington. Expressed emotion in the families of patients with schizophrenia and its influence on the course of illness. Soc Psychiatr Psychiatry Epidemiol. 1994; 29 (2): $61-65$.

25. Secker J, Grove B, Seebohm P. Challenging barriers to employment, training and education for mental health service users: the service user's perspective. I Mental Health. 2001; 10: 395-404.

26. Gaite L, Vazgueze-Barguero JI, Borrac C, Ballesteros J, Schene A, Welcher B et al. Quality of life in patients with schizophrenia in five Europian countries: the Epsilon study. Acta Psychiatr Scand. 2002 Apr; 105 (4): 283-92. 27. Hijzen A, Gorh H, Hine R. International out-sourcing and skilled structure of labour demand in the United Kingdom. The Economic Journal. 2005; 115: 860-878.

28. Priebe S, Warner R, Hubschmid T, Eckle I. Employment, attitude toward work, and quality of life among people with schizophrenia in three countries. Schizophr Bull. 1998; 24(3): 469-477.

29. Cook JA, Ranzzano L. Voctional rehabilitation for persons with schizophrenia: recent research and implications for practice. Schizophr Bull. 2000; 26: 204-208.

30. Marwaha S, Johnson S. Schizophrenia and employment: a review. Soc Psychiatry and Psychiatr Epidemiology. African Health Sciences Vol 16 Issue 4, December, 2016
2004; 39: 337-349.

31. Warner R, Polak P. The economic advancement of the mentally ill in the community: Economic choices and disincentive. Comm Mental Health J. 1995; 31: 477-492.

32. Overall JE, Gorham DR. Brief Psychiatric Rating Scale. Psychol Reports. 1962; 10: 799-812.

33. Singh MM, Kay SR. A comparative study of haloperidol and chlorpromazine in terms of clinical effects and therapeutic reversal with benztropine in schizophrenia: Theoretical implications for potency differences among neuroleptics. Psychopharmacologia. 1975a ; 43: 103-113.

34. Buchanan RW, Kreyenbuhl J, Kelly DL. The 2009 schizophrenia psychopharmacological treatment recommendations and summary statements. Schizophr Bull. 2010; 36: 71.

35. Dixon LB, Lehman AF, Levine J. Conventional antipsychotic medications for schizophrenia. Schizophr Bull. 1995; 21: 567.

36. Leung A, Cheu P. Sex differences in schizophrenia; a review of the literature. Acta Psychiatr Scand Suppl. 2000; 401: 3-38.

37. Ochoa S, Usall J, Labad X, Kulkami. Gender differences in schizophrenia and first psychosis: A comprehensive literature review. Schizophre Res Treatment. 2012; 27: 9-18. 916198. doi: 10. 1155/2012/916198. Epub 2012 Apr 8.

38. Canuso CM, Pandina G. Gender and schizophrenia. Psychopharmacol Bull. 2007; 40 (4): 178-90.

39. Kindler KS, Walsh T. Gender and schizophrenia: result of an epidemiologically-based family study. Br J Psychiatry. 1995; 167: 184-92.

40. Meltzer HY, Rabinowitz J, Lee MA, Cola PA, Ranjan $\mathrm{R}$, Findling RL et al. Age at onset and gender of schizophrenic patients in relation to neuroleptic resistance. Am J Psychiatry. 1997; 154 (4): 475 - 82.

41. Hamhtecht M, Maurer H K, Hafner LI. Gender difference in schizophrenia in three cultures. Results of WHO collaborative study. Soc Psychiatr and Psychiatr Epidemiology. 1992; 27: 117 - 21.

42. Brandy N, McCain GC. Living with schizophrenia: A family perspective. The online Journal in Nursing. 2004 Nov; 10 (1): 7.

43. Schwartz C, Gidron R. Parents of mentally ill adult children living at home: Rewards of care giving. Health Soc Work, 2002; 27: 145-154.

44. Wong, DF, Lok PW. Factors influencing expressed emotion found between Chinese caregivers and their relatives with schizophrenia in Hong Kong: a qualitative analysis. Soc Work Mental Health. 2002; 1: 61-81. 